\title{
Ultrasound-Assisted Extraction of Polysaccharides from Volvariella volvacea: Process Optimization and Structural Characterization
}

\author{
Feng-Jie Cui ${ }^{1,3, *}$, Li-Sun Qian ${ }^{1}$, Wen-Jing Sun ${ }^{1,3, *}$, Jin-Song Zhang ${ }^{2}$, Yan Yang ${ }^{2, *}, \mathrm{Na} \mathrm{Li}^{1}$, \\ Hai-Ning Zhuang ${ }^{2}$ and $\mathrm{Di} \mathrm{Wu}{ }^{2}$ \\ 1 School of Food and Biological Engineering, Jiangsu University, Zhenjiang 212013, China; \\ 18352862482@163.com (L.-S.Q.); 18852862665@163.com (N.L.) \\ 2 National Engineering Research Center of Edible Fungi, Shanghai Academy of Agricultural Sciences, \\ Shanghai 201403, China; 18918162047@189.cn (J.-S.Z.); zhuanghaining@saas.sh.cn (H.-N.Z.); \\ wudi@saas.sh.cn (D.W.) \\ 3 Parchn Sodium Isovitamin C Co. Ltd., Dexing 334221, China \\ * Correspondence: fengjiecui@163.com (F.-J.C.); juswj@163.com (W.-J.S.); yangyan@saas.sh.cn (Y.Y.); \\ Tel.: +86-511-8878-0226 (F.-J.C.)
}

Received: 5 June 2018; Accepted: 7 July 2018; Published: 13 July 2018

\begin{abstract}
The aims of the present study were to optimize the operational parameters to maximize the yield of ultrasound-assisted polysaccharide extraction from Volvariella volvacea (straw mushroom) fruiting bodies by using for the first time one-factor-at-a-time and three-level Box-Behnken factorial designs. A maximum polysaccharide yield of $8.28 \pm 0.23 \%$ was obtained under the optimized conditions of ultrasound power of $175 \mathrm{~W}$, extraction temperature of $57^{\circ} \mathrm{C}$, extraction time of $33 \mathrm{~min}$, and the ratio of liquid to raw material of 25:1, respectively. Compared to the hot-water extraction, the ultrasound-assistance favored the extraction of polysaccharides from $V$. volvacea for its higher polysaccharide yield and efficiency. Further preliminary polysaccharide structural characterization indicated that ultrasound treatment affected the monosaccharide compositions and ratios, and molecular weight range of polysaccharides extracted from $V$. volvacea.
\end{abstract}

Keywords: Volvariella volvacea; polysaccharide; ultrasound-assisted extraction; optimization; response surface methodology; structural characterization

\section{Introduction}

Edible/medicinal fungi or mushrooms, generally regarded as healthy foods and nutraceutical products, continue to attract growers' and researchers' attention, with an over 30-fold increase of world production and consumption ratios since 1978 [1-3]. Polysaccharides and polysaccharide-protein or peptide complexes are major health-benefitting macromolecules of edible/medicinal mushrooms, showing notable anti-tumor [4], immunomodulatory [5], anti-inflammatory [6] and antioxidative effects [7]. For their nontoxicity, natural origin and few side-effects, polysaccharides in mushrooms have been widely applied as nutraceuticals for nutraceutical product development or as ingredients for functional food production [8].

Volvariella volvacea (straw mushroom) is a typical tropical/subtropical species of edible mushroom presenting unique tasty/texture and nutritional values. With an estimated annual production of 330,000 tons China accounts for over $80 \%$ of the global production $[9,10]$. It contains $25.9-29.6 \%$ of protein and $2.24-3.6 \%$ of fat (per $100 \mathrm{~g}$ of dried fruiting bodies), and higher vitamin $C$ levels than many vegetables and fruits [11]. Polysaccharides such as the $(1 \rightarrow 3)-\beta$-D-glucans purified from cultured mycelia and fruiting body of $V$. volvacea have been proved to show potent antitumor activity against 
Sarcoma 180 solid tumors implanted in mice [12,13]. However, few references related to maximizing the $V$. volvacea polysaccharide extraction yield are available up to now.

Conventional methods to extract polysaccharides from mushrooms generally involve water or chemicals (acids or alkalis) along with high temperatures or pressures [14-16]. However, the long processing time (over $2 \mathrm{~h}$ ) and low extraction yield and efficiency are the drawbacks for industrial application [17]. Hence, seeking an effective strategy to decrease the processing time and increase the extraction efficiency, and evaluating the polysaccharide structure changes occurring during extraction are still valuable objectives to exploit and apply these mushroom polysaccharides, both industrially and functionally.

Recently, enzyme-assistance, pulsed electric fields, ultrasound and microwave irradiation have been proposed for extracting maximum amounts of mushroom polysaccharides [18-20]. Among these, ultrasound-assisted extraction has received wide interest due to its easy operation, less energy input and improved efficiency under mild reaction conditions [21-23]. For example, ultrasound assistance (US) benefited the extraction of (1-3; $1-6)$ - $\beta$-D-glucan from G. lucidum fruiting bodies with a highest maximum yield of $107.13 \mathrm{mg}$ within $1 \mathrm{~h}$ [24]. By comparing FTIR spectra and scanning electron microscopy results, it was proposed that ultrasound treatment destroyed the noncovalent intra- and inter-molecular bonds, and increased the polysaccharide dispersion or unfolding levels and hydrophilic groups became exposed to water molecules, which benefits the aqueous solubility of polysaccharide molecules [25]. Operational parameters including ultrasound power and frequency, extraction time and temperature would directly affect the polysaccharide extraction yields [26-28]. The maximum crude polysaccharide yield $(9.66 \pm 0.18 \%)$ of Hibiscus rosa-sinensis with strong in vitro scavenging activities on DPPH and hydroxyl radicals was obtained by optimizing the levels of factors such as ultrasonic power, extraction time, extraction temperature, and the water-to-raw material ratio by using response surface methodology (RSM) and Box-Behnken design (BBD) [29]. However, up to now, the references related to the extraction process optimization and characterization of Volvariella volvacea polysaccharide are still lacking. Hence, the present study mainly aimed to: (1) evaluate the application of an ultrasound-assisted extraction method to extract polysaccharides from $V$. volvacea fruiting bodies for the first time; (2) maximize the yield the $V$. volvacea polysaccharide by optimizing the process parameters using response surface methodology, and (3) initially characterize and compare the structural properties of polysaccharides extracted by conventional and ultrasound-assisted methods for further large-scale application.

\section{Results and Discussion}

\subsection{One-Factor-At-A-Time Experiments}

\subsubsection{Effect of Ultrasound Frequency}

Ultrasound frequency affects the purity of extracted compounds and the process cost and efficiency [30]. The effect of ultrasound frequencies ranging from $20 \mathrm{KHz}$ to $60 \mathrm{KHz}$ on UAE-VVP yield was investigated with an ultrasound power of $150 \mathrm{~W}$, extraction temperature of $50^{\circ} \mathrm{C}$, extraction time of $20 \mathrm{~min}$, liquid/material ratio of 20:1, and number of extractions of 1. As shown in Figure 1a, an increase in the ultrasound frequency showed no significant influence on UAE-VVP yield, with a slight yield decrease from $6.82 \%$ to $6.16 \%$. Similarly, an increase of ultrasonic frequency from 45 to $80 \mathrm{KHz}$ decreased the yield of Tricholoma matsutake polysaccharides from 5.55\% to 5.38\% [31]. Therefore, an ultrasound frequency of $20 \mathrm{KHz}$ was chosen for the further experiments. 

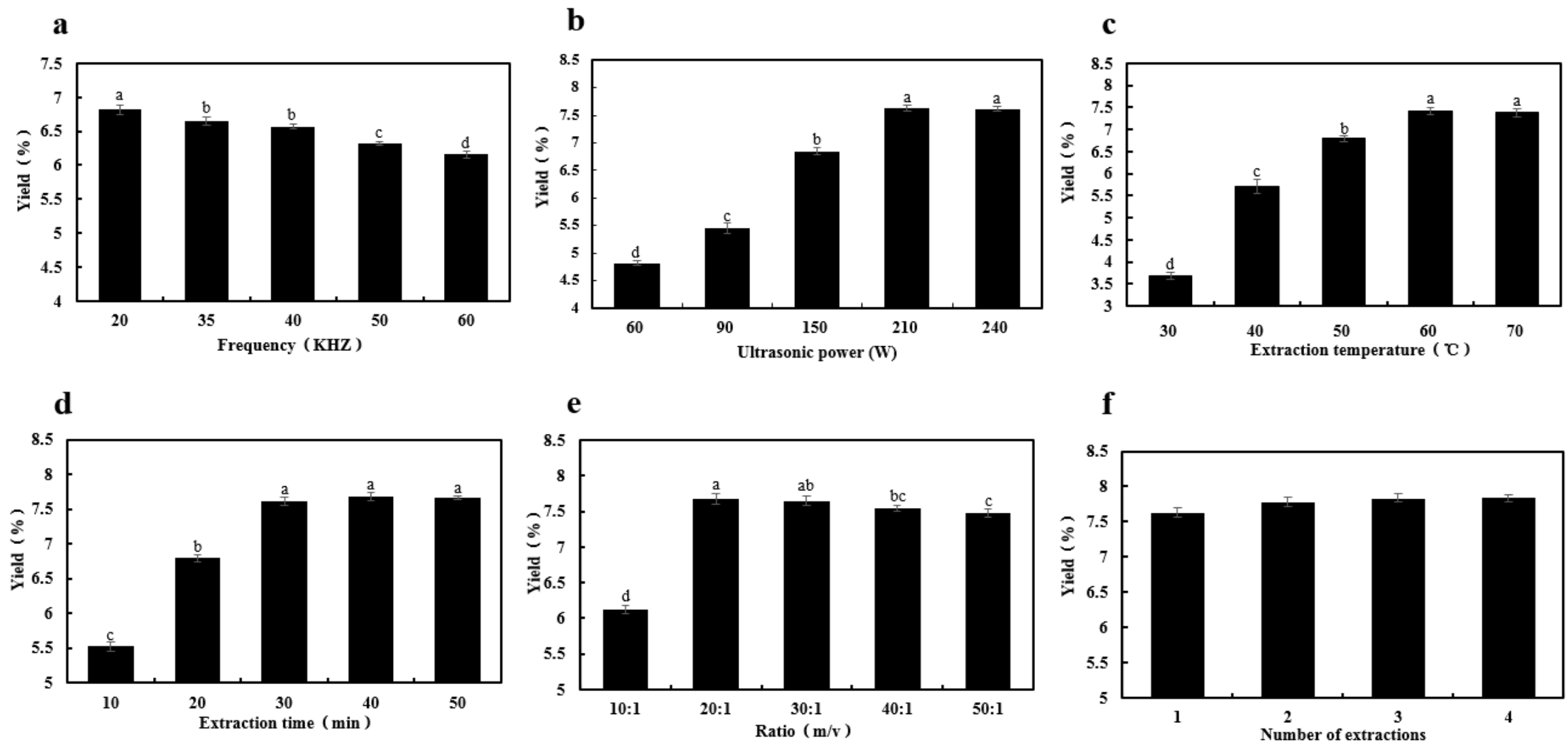

Figure 1. Effect of ultrasound frequency (a), ultrasound power (b), extraction temperature (c), extraction time (d), ratio of liquid to raw material (e) and number of extractions (f) on the yield of UAP-VVP (a-d represent the significant differences between various experiments for $p<0.05)$. 


\subsubsection{Effect of Ultrasound Power}

Generally, ultrasound power could increase molecules' solubility by destroying the intra-and inter-molecular bonds and increasing the contact efficiency between hydrophilic groups with extraction solvents [32]. Herein, five ultrasound powers ranging from $30 \mathrm{~W}$ to $240 \mathrm{~W}$ were used for investigating the influence of ultrasound power on the polysaccharide yield of $V$. volvacea fruiting bodies with the set conditions of ultrasound frequency of $20 \mathrm{KHz}$, extraction temperature of $50{ }^{\circ} \mathrm{C}$, extraction time of $20 \mathrm{~min}$, liquid/material ratio of 20:1, and number of extractions of 1, respectively. As shown in Figure $1 \mathrm{~b}$, the increase of ultrasound power from $60 \mathrm{~W}$ to $210 \mathrm{~W}$ improved the polysaccharide yield from $4.82 \%$ to $7.63 \%$. However, further increase of ultrasound power to $240 \mathrm{~W}$ resulted in the slight decrease of polysaccharide yield to $7.59 \%$. Similarly, ultrasound power of over $100 \mathrm{~W}$ had a negative effect on the extraction yield of H. rosa-sinensis leaves crude polysaccharide (HRLP) [29]. Therefore, around $150 \mathrm{~W}$ of ultrasound power was selected for further optimization with a Box-Behnken design.

\subsubsection{Effect of Extraction Temperature}

Ultrasound extraction temperature affects the purity of extracted compounds and the process cost and efficiency [33]. Figure 1c presents the influence of temperature on the polysaccharide yield of $V$. volvacea fruiting bodies. The extraction was conducted at five extraction temperatures varying from $30{ }^{\circ} \mathrm{C}$ to $70{ }^{\circ} \mathrm{C}$. V. volvacea polysaccharide yield was significantly affected by the temperature $(p<0.01)$. The maximum polysaccharide yield of $7.42 \%$ was obtained at $60^{\circ} \mathrm{C}$ after 20 min of extraction. Generally, a higher temperature would benefit the polysaccharides solubility and extraction yield. For instance, Afshari et al. found that $95{ }^{\circ} \mathrm{C}$ was an optimal temperature for extraction of polysaccharides according for high yield and industrialization application [29]. Herein, around $50{ }^{\circ} \mathrm{C}$ of extraction temperature was selected for further statistical optimization.

\subsubsection{Effect of Extraction Time}

Long extraction times usually benefit the extraction of polysaccharides from mushrooms or other raw materials. For example, okra curd polysaccharides' (OCP) yield significantly increased to $15.7 \%$ after $6.5 \mathrm{~h}$ of extraction [34]. Figure $1 \mathrm{~d}$ gives the effect of five extraction times (10, 20, 30, 40 and $50 \mathrm{~min}$ ) on the yield of UAE-VVP with the ultrasound frequency of $20 \mathrm{KHz}$, ultrasound power of $150 \mathrm{~W}$, extraction temperature of $50{ }^{\circ} \mathrm{C}$, liquid/material ratio of $20: 1$, and number of extractions of 1 . Polysaccharide yield increased rapidly from 5.52\% to maximum level of $7.61 \%$ with the increase of extraction time from $10 \mathrm{~min}$ to $30 \mathrm{~min}$. Further increases in extraction time (beyond $30 \mathrm{~min}$ ) had no significant effect on the polysaccharide yield $(p>0.05)$. Similarly, with assistance of ultrasound, a time range of 10-30 min was suitable for $H$. rosa-sinensis leaves crude polysaccharide (HRLP) with a yield of approximately $8.8 \%$, while an extraction time of 8 min resulted in the maximum Boletus edulis mycelial polysaccharides yield of $15.22 \%$ [29,35]. Therefore, an extraction time of around 30 min was selected for further optimization.

\subsubsection{Effect of Ratio of Water to Dried Fruiting Bodies}

Different ratios $(v / w)$ of liquid to dried fruiting bodies (10:1, 20:1, 30:1, 40:1, and 50:1) were used to investigate their effects on the polysaccharide yield. As shown in Figure 1e, the maximum polysaccharide yield was $7.68 \%$ when the ratio increased to 20:1. A further increase of ratio to 50:1 led to a slight decrease of polysaccharide yield. Generally, an increase of water to dried fruiting body would lead to an increase in the extraction working volume and energy input for evaporation, which is not economical. Hence, ratios of liquid to dried fruiting bodies from 10:1 to 30:1 were selected for further BBD optimization of polysaccharide extraction. 


\subsubsection{Effect of Number of Extractions}

As shown in Figure 1f, number of extractions was set from 1 to 4 times when other extraction conditions were fixed as ultrasound frequency of $20 \mathrm{KHZ}$, ultrasound power of $150 \mathrm{~W}$, extraction time of $30 \mathrm{~min}$, extraction temperature of $50^{\circ} \mathrm{C}$ and liquid/material ratio of 20:1. The one time extraction yield of UAW-VVP was $7.63 \%$. Further increasing the number of extractions to 4 seemed to have no significant effect, with the yield of polysaccharide increasing to only $7.84 \%(p>0.05)$. Hence, extraction for one time was chosen for further experiments.

\subsection{Optimization of the Parameters by RSM}

Response surface methodology provides an empirical modeling for elucidating the effect of the independent variables, and interactive effects of each independent variable on the response [36]. In order to systemically understand the relationships between ultrasound power $\left(\mathrm{X}_{1}\right)$, extraction temperature $\left(X_{2}\right)$, extraction time $\left(X_{3}\right)$ and ratio of liquid to dried fruiting bodies $\left(X_{4}\right)$ for UAE-VVP yield, a 3-level-4-factor Box-Behnken Design (BBD) was applied with 29 experimental runs (Table 1). Table 1 shows a considerable variation in the polysaccharide yields under different extraction conditions. The polysaccharide yield from $V$. volvacea fruiting bodies ranged from 5.13\% to $8.21 \%$, and the runs \#12 and \#27 had the maximum and minimum yield values, respectively. The coefficient of determination $\left(\mathrm{R}^{2}\right)$ and adjusted coefficient of determination $\left(\mathrm{R}^{2} \mathrm{a}\right)$ were calculated as $98.81 \%$ and $97.61 \%$, respectively. This indicated that, the accuracy and general predictive ability of the polynomial model was good, and analysis of the UAE-VVP yield trends using the model was considered to be reasonable [37].

Table 1. Coded and levels of independent variables and the response used in Box-Behnken design matrix.

\begin{tabular}{|c|c|c|c|c|c|}
\hline Run & $\begin{array}{c}\text { Ultrasound } \\
\text { Power }\left(W, X_{1}\right)\end{array}$ & $\begin{array}{c}\text { Extraction Temperature } \\
\left(\text { Degrees } C, X_{2}\right)\end{array}$ & $\begin{array}{l}\text { Extraction Time } \\
\left(\min , X_{3}\right)\end{array}$ & $\begin{array}{l}\text { Extraction Ratio } \\
\left(\mathrm{mL} / \mathrm{g}, \mathrm{X}_{4}\right)\end{array}$ & Yield (\%) \\
\hline 1 & $90(-1)$ & $50(0)$ & $30(0)$ & $30(1)$ & $6.08 \pm 0.23$ \\
\hline 2 & $90(-1)$ & $60(1)$ & $30(0)$ & $20(0)$ & $7.10 \pm 0.31$ \\
\hline 3 & $210(1)$ & $50(0)$ & $40(1)$ & $20(0)$ & $7.95 \pm 0.18$ \\
\hline 4 & $150(0)$ & $50(0)$ & $30(0)$ & $20(0)$ & $7.54 \pm 0.30$ \\
\hline 5 & $150(0)$ & $40(-1)$ & $40(1)$ & $20(0)$ & $6.55 \pm 0.28$ \\
\hline 6 & $90(-1)$ & $50(0)$ & $20(-1)$ & $20(0)$ & $5.42 \pm 0.36$ \\
\hline 7 & $150(0)$ & $50(0)$ & $30(0)$ & $20(0)$ & $7.51 \pm 0.30$ \\
\hline 8 & $150(0)$ & $50(0)$ & $30(0)$ & $20(0)$ & $7.65 \pm 0.24$ \\
\hline 9 & $150(0)$ & $50(0)$ & $20(-1)$ & $30(1)$ & $6.64 \pm 0.28$ \\
\hline 10 & $90(-1)$ & $50(0)$ & $40(1)$ & $20(0)$ & $6.90 \pm 0.23$ \\
\hline 11 & $90(-1)$ & $50(0)$ & $30(0)$ & $10(-1)$ & $5.97 \pm 0.33$ \\
\hline 12 & $210(1)$ & $60(1)$ & $30(0)$ & $20(0)$ & $8.21 \pm 0.35$ \\
\hline 13 & 210(1) & $40(-1)$ & $30(0)$ & $20(0)$ & $6.89 \pm 0.38$ \\
\hline 14 & $150(0)$ & $50(0)$ & $30(0)$ & $20(0)$ & $7.75 \pm 0.27$ \\
\hline 15 & $210(1)$ & $50(0)$ & $30(0)$ & $30(1)$ & $7.96 \pm 0.19$ \\
\hline 16 & $150(0)$ & $40(-1)$ & $20(-1)$ & $20(0)$ & $5.74 \pm 0.27$ \\
\hline 17 & 150(0) & $60(1)$ & $30(0)$ & $30(1)$ & $7.94 \pm 0.33$ \\
\hline 18 & $150(0)$ & $40(-1)$ & $30(0)$ & $10(-1)$ & $5.88 \pm 0.21$ \\
\hline 19 & $150(0)$ & $50(0)$ & $40(1)$ & $10(-1)$ & $7.08 \pm 0.26$ \\
\hline 20 & $150(0)$ & $50(0)$ & $40(1)$ & $30(1)$ & $7.68 \pm 0.31$ \\
\hline 21 & $150(0)$ & $50(0)$ & $30(0)$ & $20(0)$ & $7.68 \pm 0.24$ \\
\hline 22 & $150(0)$ & $60(1)$ & $40(1)$ & $20(0)$ & $8.07 \pm 0.28$ \\
\hline 23 & $150(0)$ & $60(1)$ & $30(0)$ & $10(-1)$ & $7.38 \pm 0.37$ \\
\hline 24 & $150(0)$ & $40(-1)$ & $30(0)$ & $30(1)$ & $5.75 \pm 0.21$ \\
\hline 25 & $210(1)$ & $50(0)$ & $30(0)$ & $10(-1)$ & $7.70 \pm 0.24$ \\
\hline 26 & $210(1)$ & $50(0)$ & $20(-1)$ & $20(0)$ & $7.69 \pm 0.32$ \\
\hline 27 & $90(-1)$ & $40(-1)$ & $30(0)$ & $20(0)$ & $5.13 \pm 0.27$ \\
\hline 28 & $150(0)$ & $60(1)$ & $20(-1)$ & $20(0)$ & $7.48 \pm 0.19$ \\
\hline 29 & $150(0)$ & $50(0)$ & $20(-1)$ & $10(-1)$ & $6.22 \pm 0.24$ \\
\hline
\end{tabular}

According to the regression coefficients, along with the corresponding $p$-values, for the model of the extraction yield of $V$. volvacea polysaccharide, the linear coefficients $\left(X_{1}, X_{2}, X_{3}\right.$ and $\left.X_{4}\right)$, quadratic 
coefficients $\left(X_{1}{ }^{2}, X_{2}{ }^{2}, X_{3}{ }^{2}\right.$, and $\left.X_{4}{ }^{2}\right)$ and interaction coefficients $\left(X_{1} X_{2}\right.$ and $\left.X_{2} X_{3}\right)$ were significant at the $1 \%$ level. The combined effect of the process variables was statistically significant (model $F$-value $=82.77, p$-value $<0.0001)$. The second-order polynomial model for UAE-VVP yield $(\mathrm{Y})$ was regressed by only considering the significant terms and was shown as below:

$$
\begin{gathered}
\mathrm{Y}_{\mathrm{UEA}-\mathrm{VVP} \text { yield }}=7.63+0.82 \mathrm{X}_{1}+0.85 \mathrm{X}_{2}+0.42 \mathrm{X}_{3}+0.15 \mathrm{X}_{4}-0.16 \mathrm{X}_{1} \mathrm{X}_{2}-0.055 \mathrm{X}_{2} \mathrm{X}_{3}+0.17 \mathrm{X}_{2} \mathrm{X}_{4} \\
-0.33 \mathrm{X}_{1}^{2}-0.44 \mathrm{X}_{2}^{2}-0.28 \mathrm{X}_{3}^{2}-0.42 \mathrm{X}_{4}^{2}
\end{gathered}
$$

3D response surface plots and their corresponding contour plots were drawn on the basis of the model equation, to investigate the interactions among the variables and to determine the optimum concentration of each factor for maximum UAE-VVP yield. The contour plots affirm that the objective function is unimodal in nature, which shows an optimum in the boundaries.

Figure 2a presents the interaction relationship between the two independent variables (ultrasound power and extraction temperature) and the response variable (UAE-VVP yield) by keeping the other independent variables (extraction time and ratio) as constants (30 $\mathrm{min}$ and 20:1, respectively). It was obvious that the UAE-VVP yield showed the corresponding significant changes when ultrasound power and extraction temperature were subjected to small alterations. An increase in the UAE-VVP yield could be significantly achieved with the increases of ultrasound power and extraction temperature. Under certain condition (ultrasound power over $135 \mathrm{~W}$, coded as $-0.25 \sim 1$; extraction temperature over $48{ }^{\circ} \mathrm{C}$, coded as $-0.20 \sim 1$ ), a maximal contour ( $\mathrm{Y}_{\mathrm{UAE}-\mathrm{VVP}}$ yield $=8.21 \%$ ) could be determined (Figure 2a), meaning that further increases of ultrasound power and extraction temperature would not increase the polysaccharide yield levels significantly, which were in accordance with the results obtained in one-factor-at-a-time experiments.

Figure $2 b$ describes the effects of $X_{1}$ (ultrasound power) and $X_{3}$ (extraction time) on yield level and indicated when $X_{1}$ (ultrasound power) and $X_{3}$ (extraction time) were in the ranges of 0.41 1 (coded value), and $-0.50 \sim 0.90$ (coded value), the yield was at a high level of $8.21 \%$. The response curves demonstrated that the response value changed significantly with the low level of $X_{1}$ (ultrasound power) and $X_{3}$ (extraction time). In addition, the response curves were comparatively smooth when the $X_{1}$ (ultrasound power) and $X_{3}$ (extraction time) were all in a high level.

Figure 2c shows the effects of $X_{2}$ (extraction temperature) and $X_{4}$ (liquid/material ratio) on polysaccharide extraction. When $X_{2}$ (extraction temperature) and $X_{4}$ (liquid/material ratio) ranged from 0.50 to 1 (coded value), and -0.20 to 0.80 (coded value), the yield increased to its relatively-highest value of $8.21 \%$, consistent with the result seen in our one-factor-at-a-time experiments. Figure $2 \mathrm{c}$ also suggests that further increases over $55^{\circ} \mathrm{C}$ and $28: 1$ would not increase the polysaccharide yield level significantly. Thus, in order to obtain the higher extraction yield, an appropriate level of $X_{2}$ (extraction temperature) and $\mathrm{X}_{4}$ (liquid/material ratio) was essential. A maximum UAE-VVP yield of $8.32 \%$ by using ultrasound power $\left(\mathrm{X}_{1}\right)$ of $172.13 \mathrm{~W}$, extraction temperature $\left(\mathrm{X}_{2}\right)$ of $56.68^{\circ} \mathrm{C}$, extraction time $\left(\mathrm{X}_{3}\right)$ of $32.98 \mathrm{~min}$, ratio of liquid to raw material $\left(\mathrm{X}_{4}\right)$ of $24.45: 1$, respectively, could be predicted with the Design Expert software.

\section{Verification of Predictive Model}

The availability of the regression model (Equation (1)) of the UAE-VVP yield was tested using the calculated optimal culture composition, viz. ultrasound power $175 \mathrm{~W}$, extraction temperature $57^{\circ} \mathrm{C}$, extraction time $33 \mathrm{~min}$, ratio of liquid to raw material $\left(\mathrm{X}_{4}\right)$ of $25: 1$, with triplicate experiments. The mean value of UAE-VVP yield was $8.28 \pm 0.23 \%$, which agreed well with the predicted value $(8.32 \%)$. As a result, the models developed were considered to be accurate and reliable for predicting the UAE-VVP yield from $V$. volvacea fruiting bodies. Compared the polysaccharide (HWE-VVP) yield of $7.56 \%$ with $100{ }^{\circ} \mathrm{C}$ hot water for $2 \mathrm{~h}$, the UAE method was attractive for its higher polysaccharide yield and efficiency in a shorter time (approximately $33 \mathrm{~min}$ ). 
a

产
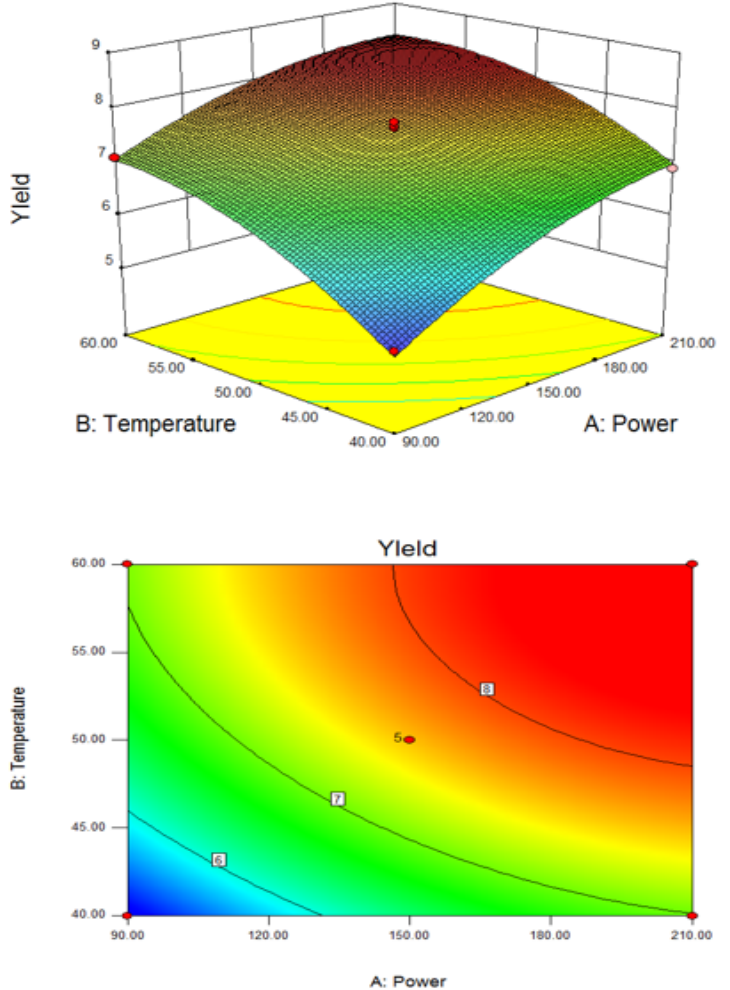

b
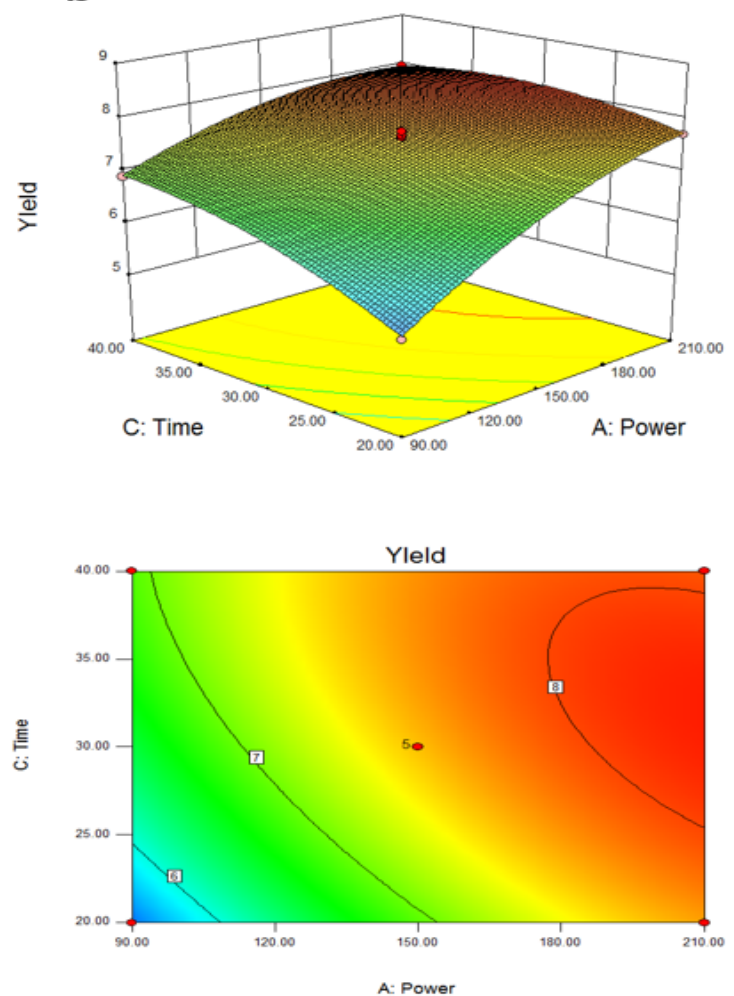

\section{C}

$\frac{0}{\frac{0}{2}}$
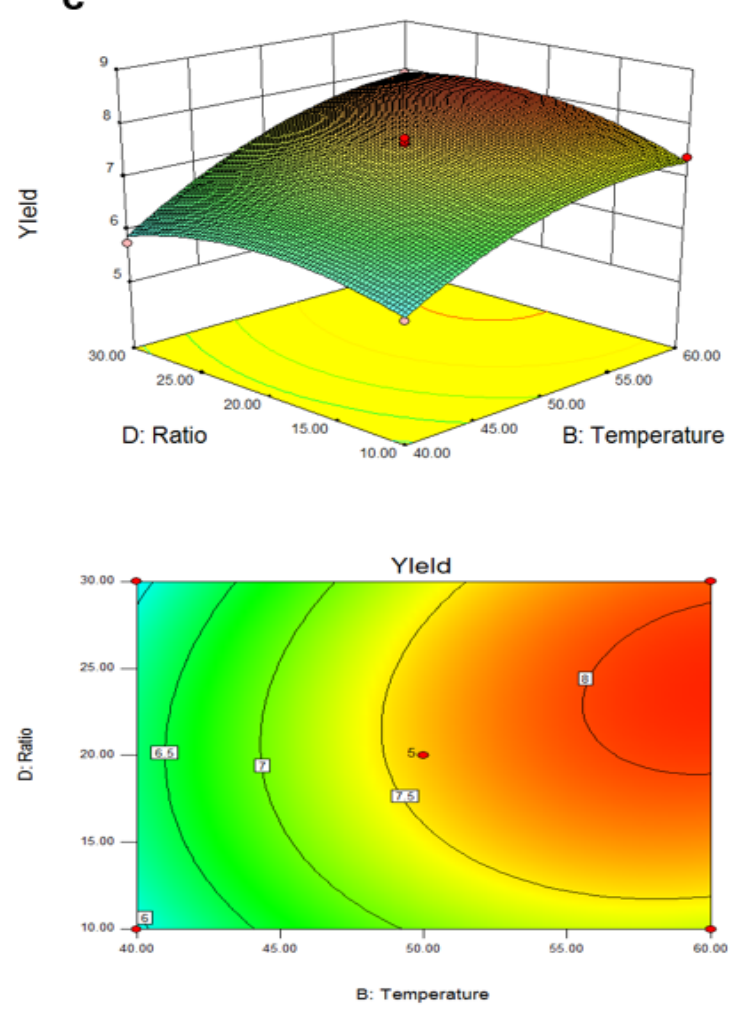

Figure 2. Response surface plots showing effects of ultrasound power (a), extraction temperature (b), extraction time and Ratio of liquid to raw material (c) on the yield of UAE-VVP. 


\subsection{Comparison of the Structural Characteristics of Polysaccharides Extracted with Hot Water and Ultrasound-Assisted Methods}

To find the possible structural changes of polysaccharides during the ultrasound treatment, the monosaccharide compositions and ratios, carbohydrate contents, average molecular weights and spectra of UAE-VVP were determined with those of HWE-VVP as a comparison. The $V$. volvacea polysaccharide fractions were obtained with hot water (HWE-VVP) and ultrasound-assisted (UAE-VVP) extractions followed with ethanol precipitation. The total carbohydrate contents in these polysaccharide fractions were determined as $65.82 \%$ and $60.78 \%$, respectively. Table 2 showed monosaccharide compositions and ratios in UAE-VVP and HWE-VVP. Two polysaccharides contained the same monosaccharide compositions of D-glucose, D-mannose and D-galactose. D-Glucose is the main sugar, with ratios of 6.58 and 4.79 in UAE-VVP and HWE-VVP, respectively, which indicated that the main chain of these polysaccharides was possibly a glucan. The ultrasound treatment possibly broke the side chain containing D-mannose and D-galactose, which resulted in the increase of glucose ratio (6.58) in UAE-VVP.

Table 2. Monosaccharide composition of VVP extracted with ultrasound-assisted extraction (UAE) and hot water extraction (HWE).

\begin{tabular}{cccc}
\hline & \multicolumn{3}{c}{ Molar Ratio } \\
\cline { 2 - 4 } & D-Mannose (22.008 $\mathbf{~ m i n )}$ & D-Glucose (22.898 $\mathbf{~ m i n})$ & D-Galactose (23.545 min) \\
\hline UAE-VVP & 1 & 6.58 & 1.12 \\
HWE-VVP & 1 & 4.79 & 1.14 \\
\hline
\end{tabular}

The average molecular weights of UAE-VVP and HWE-VVP were determined by HPSEC and shown in Table 3. UAE-VVP showed three fractions in the HPSEC chromatography with Mws and content percentages of 255.42 KDa, 2.69 KDa, 0.1167 KDa and 24.55\%, 46.87\%, 28.58\%, respectively, while HWE-VVP had two peaks with Mws and content percentages of $357.56 \mathrm{KDa}$, 2.47 KDa, and $92.08 \%, 7.92 \%$, respectively. The results also proved that the ultrasound treatment possibly partially destroyed the polysaccharide chains to produce a fraction in UAE-VVP. The lower extraction temperature for UAE also possibly contributed to the lower $\mathrm{M}_{\mathrm{W}}$ of UAE-VVP, which was less effective for extraction and dissolution of the higher- $\mathrm{M}_{\mathrm{W}}$ polysaccharides [38]. Similarly, the 120-min sonication decreased the molecular weight of waxy maize starch from around $3 \times 10^{6}$ to $2 \times 10^{5}$ [39]. Cheung et al. also found that all the polysaccharide-protein (PSP) complexes from three medicinal mushrooms (Grifola frondosa, Coriolus versicolor and Lentinus edodes) using ultrasound-assisted extraction (UAE) showed an increase of lower- $\mathrm{M}_{\mathrm{W}}$ peaks and a decrease of higher- $\mathrm{M}_{\mathrm{W}}$ peaks in peak area and number, or the shift of $\mathrm{M}_{\mathrm{W}}$ distribution from high to low $\mathrm{M}_{\mathrm{W}}$ range compared with those by how water extraction [40].

Table 3. Retention time, Mw and amount of soluble polysaccharide fractions extracted with ultrasound-assisted extraction (UAE) and hot water extraction (HWE).

\begin{tabular}{ccccc}
\hline Samples & Peak No & Retention Time (min) & $\mathbf{M}_{\mathbf{W}}(\mathbf{K D a})$ & Area Percentages (\%) \\
\hline \multirow{2}{*}{ HWE-VVP } & 1 & 13.41 & 357.56 & 92.08 \\
& 2 & 16.98 & 2.47 & 7.92 \\
\multirow{2}{*}{ UAE-VVP } & 1 & 13.17 & 255.42 & 24.55 \\
& 2 & 16.95 & 2.69 & 46.87 \\
& 3 & 19.37 & 0.12 & 28.58 \\
\hline
\end{tabular}

The UV spectra and FTIR-ATR spectra of UAE-VVP and HWE-VVP are shown in Figure 3. There was no UV absorption at the characteristic absorption peak of $260 \mathrm{~nm}$ and $280 \mathrm{~nm}$, indicating that the sample contained extremely low content of proteins or nucleic acids (Figure 3A). Figure 3B gives the 
FTIR-ATR spectra of UAE-VVP and HWE-VVP. The large broad band at $3420 \mathrm{~cm}^{-1}$ corresponds to the typical hydroxyl group (O-H) absorption [41]. The intense band around $2932 \mathrm{~cm}^{-1}$ was attributed to the presence of the $\mathrm{C}-\mathrm{H}$ stretching vibration [42]. The special characteristic of the absorption caused by asymmetric stretching vibration of carbonyl $(\mathrm{C}=\mathrm{O})$ in polysaccharides appeared at $1645 \mathrm{~cm}^{-1}$. The minor peaks at $1371 \mathrm{~cm}^{-1}$ and $1027 \mathrm{~cm}^{-1}$ confirmed the variable angle vibration of $\mathrm{C}-\mathrm{O}-\mathrm{H}$. Otherwise, the minor peak noted at $890 \mathrm{~cm}^{-1}$ indicated the presence of the C-O-C stretching of glycosidic linkages [43]. The FT-IR characterization of UAE-VVP thus displayed the typical absorption peaks of polysaccharides [44]. There were no significant differences in the FTIR spectra of UAE-VVP and HWE-VVP. A similar phenomenon was also observed by Yan et al., whereby no considerable differences in the chemical structures of three Corbicula fluminea polysaccharides were observed after using ultrasound with three-phase partitioning (USTPP), ultrasound extraction (USE) and three-phase partitioning (TPP) [25].
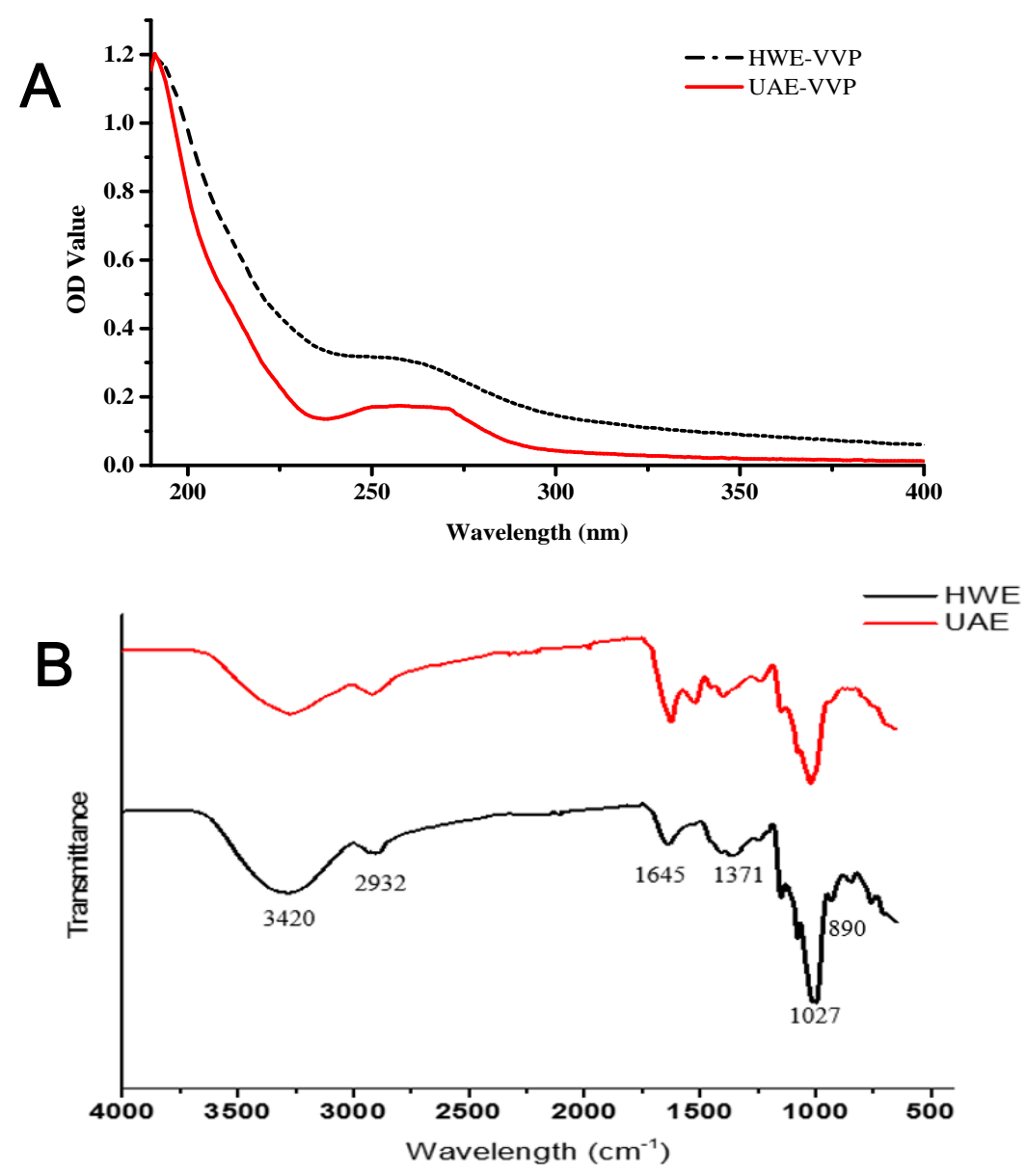

Figure 3. UV spectrograms (A) and Fourier transform infrared spectra (B) of HWE-VVP and UAE-VVP.

\section{Materials and Methods}

\subsection{Materials}

Volvariella volvacea (straw mushroom) was cultivated at $32 \pm 2{ }^{\circ} \mathrm{C}$ and $90 \%$ of relative humidity by Jiangnan Biotech Co., Ltd. (Zhenjiang, China). The fruiting body at egg stage was harvested after 4-week cultivation, freezing-dried to constant weight, and ground into powder (approximately 80-mesh size) with an electric mill for further extracting polysaccharides. Standard monosaccharides including glucose, xylose, arabinose, rhamnose, mannose, galactose and inositol were purchased from 
Sigma (St. Louis, MO, USA). Other chemicals and solvents were of analytical grade and used without further purification.

\subsection{Polysaccharide Extraction}

\subsubsection{Hot Water Extraction (HWE)}

As shown in Figure 4, hot water extraction (HWE) were carried out twice by mixing $50 \mathrm{~g}$ of ground $V$. volvacea fruiting bodies with $1000 \mathrm{~mL}$ of distilled water, heating for $100{ }^{\circ} \mathrm{C}$ for $2 \mathrm{~h}$ using a water bath, and centrifuging at $10,000 \times g$ for $20 \mathrm{~min}$. The combined supernatants were concentrated under reduced pressure and precipitated with a final concentration of $75 \%$ ethanol for $12 \mathrm{~h}$ at $4{ }^{\circ} \mathrm{C}$. The precipitation was collected by centrifugation $(10,000 \times g, 15 \mathrm{~min})$, followed by dialyzing against distilled water, and lyophilized to yield crude polysaccharides (HWE-VVP).

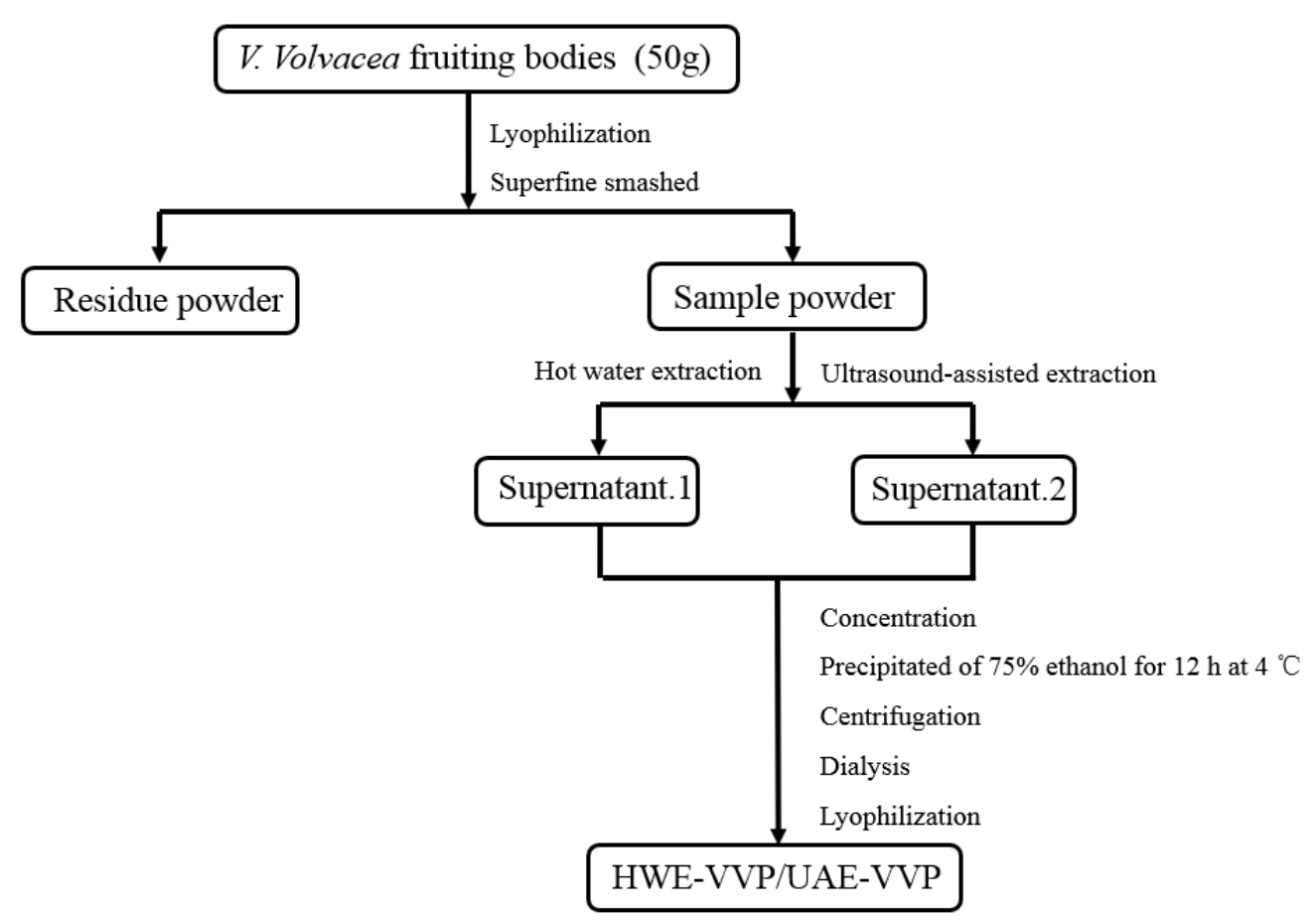

Figure 4. Stepwise scheme of $V$. volvacea polysaccharide extraction using ultrasound-assisted extraction (UAE) and hot water extraction (HWE).

\subsubsection{Ultrasound-Assisted Extraction (UAE)}

Ultrasound-assisted extraction (UAE) was conducted by using ultrasound equipment consisting of an ultrasonic reaction chamber (internal dimensions: $240 \mathrm{~mm}$ width $\times 207 \mathrm{~mm}$ length $\times 215 \mathrm{~mm}$ height, Shangjia Biotechnology Co., Wuxi, Jiangsu, China) equipped with three alternating dual-frequency plates, a water bath for balancing the treatment temperature, and a PLC control panel [45]. The ultrasound generators were installed at three sides of the bath reactor. The maximum output acoustic power of each plate is $300 \mathrm{~W}$.

Fifty grams of ground $V$. volvacea fruiting bodies was mixed with distilled water and placed in reaction chamber for ultrasonic extraction. The other procedures to obtain the polysaccharide (UAE-VVP) with ultrasound-assisted extraction method were similar to those of HWE, including centrifugation to collect the supernatant, reduced pressure concentration, ethanol precipitation, dialysis against distilled water, and lyophilization. 


\subsection{Optimization of Extraction Parameters}

One-factor-at-a-time experiments were conducted to evaluate the effects of ultrasound frequency (from $20 \mathrm{KHz}$ to $60 \mathrm{KHz}$ ), ultrasound power (from $60 \mathrm{~W}$ to $240 \mathrm{~W}$ ), extraction temperature (from $30{ }^{\circ} \mathrm{C}$ to $70{ }^{\circ} \mathrm{C}$ ), extraction time (from $10 \mathrm{~min}$ to $50 \mathrm{~min}$ ), number of extractions (from 1 to 4 times) and liquid/solid ratio (from 10:1 to 50:1) on the polysaccharide yields of $V$. volvacea fruiting bodies.

Response surface methodology (RSM) was used to investigate the influence of ultrasound power $\left(X_{1}\right)$, extraction temperature $\left(X_{2}\right)$, extraction time $\left(X_{3}\right)$ and liquid/solid ratio $\left(X_{4}\right)$ on the polysaccharide yields of $V$. volvacea fruiting bodies. A Box-Behnken design with four factors and three levels was used for fitting a second order response surface [46].

Table 1 gave the factors, their values, and the experimental design, respectively. A mathematical model, describing the relationships between the response (the polysaccharide yield) and the process parameters in second order equation, was developed as follows:

$$
Y=A_{0}+\sum A_{i} X_{i}+\sum A_{i i} X_{i}^{2}+\sum A_{i j} X_{i} X_{j}
$$

where $Y$ is the predicted response variable; $A_{0}, A_{i}, A_{i i}, A_{i j}$ are constant regression coefficients of the model, and $X_{i}, X_{j}(i=1,4 ; j=1,4, i \neq j)$ represent the independent variables (extraction parameters) in the form of coded values. The accuracy and general ability of the above polynomial model could be evaluated by the coefficient of determination $\mathrm{R}^{2}$.

\subsection{Analysis}

\subsubsection{Polysaccharide Yield}

Polysaccharide yield (\%) of $V$. volvacea fruiting bodies was calculated by dividing the amount of extracted crude polysaccharide by the weight of $V$. volvacea fruiting bodies.

\subsubsection{Carbohydrate Content and Monosaccharide Composition Analysis}

Carbohydrate content of HWE-VVP or UAE-VVP was determined at $490 \mathrm{~nm}$ by the phenolsulfuric acid method with D-glucose as a standard [47]. Monosaccharide compositions and their ratios in HWE-VVP or UAE-VVP were determined by absolute hydrolysis [48]. Briefly, $30 \mathrm{mg}$ HWE-VVP or UAE-VVP were hydrolyzed with $0.3 \mathrm{~mL} 72 \%(w / v)$ sulfuric acid for $30 \mathrm{~min}$ at $30{ }^{\circ} \mathrm{C}$, followed with addition of $8.4 \mathrm{~mL}$ of distilled water and incubation at $121^{\circ} \mathrm{C}$ for $1 \mathrm{~h}$. The hydrolysate was neutralized with $\mathrm{CaCO}_{3}$, evaporated to dryness, and acetylated with $\mathrm{Ac}_{2} \mathrm{O}$-pyridine at $90{ }^{\circ} \mathrm{C}$ for 30 min. Xylose, glucose, arabinose, rhamnose, mannose, and galactose were derivatized as standard. Inositol was used as an internal standard. The resulting alditol acetate was analyzed by gas chromatography using an Agilent Technologies 7890A Network gas chromatograph using a capillary column (HP-1 $2.1 \mathrm{~m} \times 0.2 \mathrm{~mm}$, i.d.) and a flame ionization detector (FID) (Hewlett-Packard, Avondale, PA, USA) with nitrogen as carrier gas $(50 \mathrm{~mL} / \mathrm{min})$. The temperatures for injector and the detector were kept at $280{ }^{\circ} \mathrm{C}$ and $300{ }^{\circ} \mathrm{C}$, respectively. The products were identified by typical retention times of corresponding standards.

\subsubsection{Molecular Weight Analysis by Gel Permeation Chromatography}

The molecular weight of HWE-VVP or UAE-VVP was determined by high performance size exclusion chromatography (HPSEC) on a Waters 1525 HPLC system (Waters Corporation, Milford, MA, USA) equipped with an Ultrahydrogel Linear $(7.8 \mathrm{~mm} \times 300 \mathrm{~mm}$, Waters Corporation) and a 2414 refractive index detector. HWE-VVP or UAE-VVP $(2.0 \mathrm{mg})$ were dissolved by $1.0 \mathrm{~mL} \mathrm{NaNO}_{3}$ $(0.1 \mathrm{M})$ and loaded into the chromatography system $(15 \mu \mathrm{L})$. The columns were maintained at $45^{\circ} \mathrm{C}$ and eluted with $0.1 \mathrm{M} \mathrm{NaNO}_{3}$ at a flow rate of $0.9 \mathrm{~mL} / \mathrm{min}$. Preliminary calibration of the column was conducted by using standards dextrans (Sigma-Aldrich, St. Louis, MO, USA) with different molecular 
weights. The molecular weight $(\mathrm{Mw})$ of HWE-VVP or UAE-VVP was calculated by comparison with the calibration curve [49].

\subsubsection{UV and FTIR}

The aqueous solution of HWE-VVP or UAE-VVP was formulated into a $1 \mathrm{mg} / \mathrm{mL}$ aqueous solution and scanned with a UV spectrophotometer at a wavelength of 190-400 nm. The UV spectrum of the HWE-VVP or UAE-VVP solution was obtained at room temperature compared with water.

The Fourier Transform-Infrared Attenuated Total Reflectance (FTIR-ATR) spectra of HWE-VVP or UAE-VVP was detected using a Card-Fourier Infrared Spectrometer (Nicolet, Madison, WI, USA) to determine the chemical bonds, chemical nature and functional groups of extracted polysaccharides. The spectrum was recorded from 400 to $4000 \mathrm{~cm}^{-1}$ by accumulation of 16 scans using resolution setting of $4 \mathrm{~cm}^{-1}$ and plotted as \% transmittance $v$ s. wavenumber [50].

\subsection{Statistics}

Each experiment was repeated three times using duplicate samples. The results were expressed as means \pm standard deviations. Statistical comparisons were made by one-way analysis of variance (ANOVA), followed by Duncan's multiple-comparison test [51,52]. Differences were considered significant when the $p$-values were $<0.05$ [53]. The 3D response surface and contour plot analysis were made by keeping one independent variable at constant level, changing the other two independent variables with Design Expert software version 11 (Stat-Ease, Inc., Minneapolis, MN, USA).

\section{Conclusions}

The present study presented the positive effects of an ultrasound-assisted method on the yield and efficiency of polysaccharide extraction from Volvariella volvacea fruiting bodies. The operational parameters and levels for $V$. volvacea polysaccharide extraction were selected and optimized by using one-factor-at-a-time and response surface methodology. Under optimal conditions of ultrasound power of $175 \mathrm{~W}$; extraction temperature of $57^{\circ} \mathrm{C}$; extraction time of $33 \mathrm{~min}$; and ratio of liquid to raw material of 25:1, respectively, the verified experimental value of polysaccharide yield was $8.28 \pm 0.23 \%$. UAE-VVP showed significant differences of monosaccharide compositions and ratios, and molecular weight range from those observed in HWE-VVP. Studies on the fine structure information and immunomodulating activities of UAE-VVP and HWE-VVP are ongoing in our lab for further evaluating the application of ultrasound-assisted method for polysaccharide extraction from $V$. volvacea fruiting bodies as potential functional ingredients in the health food and nutrition industries.

Author Contributions: Conceptualization F.-J.C., W.-J.S. and Y.Y.; Methodology and investigation, F.-J.C., L.-S.Q., N.L.; Data Analysis and Software, L.-S.Q., J.-S.Z., D.W. and H.-N.Z.; Writing-Original Draft Preparation, L.-S.Q., F.-J.C.; Writing-Review \& Editing, F.-J.C., W.-J.S., and Y.Y.

Funding: This research was funded by Natural Science Foundation of China [31771961], Shanghai Agriculture Applied Technology Development Program [2017, No. 9], Priority Academic Program Development of Jiangsu Higher Education Institutions (PAPD), and Science \& Technology Platform Construction Program of Jiangxi Province. The APC was funded by Natural Science Foundation of China [31771961], Shanghai Agriculture Applied Technology Development Program [2017, No. 9] and Priority Academic Program Development of Jiangsu Higher Education Institutions.

Acknowledgments: We thanks the Jiangnan Biotech Co., Ltd. (Zhenjiang, China) for providing fruiting bodies of Volvariella volvacea (straw mushroom) for experiments.

Conflicts of Interest: The authors declare no conflict of interest.

\section{References}

1. Corrêa, R.C.G.; Brugnari, T.; Bracht, A.; Peralta, R.M.; Ferreira, I.C.F.R. Biotechnological, nutritional and therapeutic uses of Pleurotus spp. (Oyster mushroom) related with its chemical composition: A review on the past decade findings. Trends Food Sci. Technol. 2016, 50, 103-117. [CrossRef] 
2. Royse, D.J.; Baars, J.; Tan, Q. Current overview of mushroom production in the world. In Edible and Medicinal Mushrooms: Technology and Applications, 1st ed.; John Wiley \& Sons Ltd.: Chichester, UK, 2017; pp. 5-13.

3. Zhang, B.B.; Hu, P.F.; Huang, J.; Hu, Y.D.; Chen, L.; Xu, G.R. Current advances on the structure, bioactivity, synthesis and metabolic regulation of novel ubiquinone derivatives in the edible and medicinal mushroom Antrodia cinnamomea. J. Agric. Food Chem. 2017, 65, 10395-10405. [CrossRef] [PubMed]

4. Liu, X.; Sun, Z.L.; Jia, A.R.; Shi, Y.P.; Li, R.H.; Yang, P.M. Extraction, preliminary characterization and evaluation of in vitro antitumor and antioxidant activities of polysaccharides from Menthe piperita. Int. J. Mol. Sci. 2014, 15, 16302-16319. [CrossRef] [PubMed]

5. Tan, W.; Yu, K.Q.; Liu, Y.Y.; Ouyang, M.Z.; Yan, M.H.; Luo, R.; Zhao, X.S. Anti-fatigue activity of polysaccharides extract from Radix Rehmanniae preparata. Int. J. Biol. Macromol. 2012, 50, 59-62. [CrossRef] [PubMed]

6. Lajili, S.; Deghrigue, M.; Bel, H.A.H.; Muller, C.D.; Bouraoui, A. In vitro immunomodulatory activity and in vivo anti-inflammatory and analgesic potential with gastroprotective effect of the Mediterranean red alga Laurencia obtusa. Pharm. Biol. 2016, 54, 2486-2495. [CrossRef] [PubMed]

7. Chen, G.J.; Zhang, S.Q.; Ran, C.X.; Wang, L.S.; Kan, J.Q. Extraction, characterization and antioxidant activity of water-soluble polysaccharides from Tuber huidongense. Int. J. Biol. Macromol. 2016, 91, 431-442. [CrossRef] [PubMed]

8. Xie, J.H.; Tang, W.; Jin, M.L.; Li, J.E.; Xie, M.Y. Recent advances in bioactive polysaccharides from Lycium barbarum L. Zizyphus jujuba Mill, Plantago spp. and Morus spp.: Structures and functionalities. Food Hydrocoll. 2016, 60, 148-160. [CrossRef]

9. Cai, Y.J.; Chapman, S.J.; Buswell, J.A.; Chang, S.T. Production and distribution of endoglucanase, cellobiohydrolase, and $\beta$-glucosidase components of the cellulolytic system of Volvariella volvacea, the edible straw mushroom. Appl. Environ. Microbiol. 1999, 65, 553-559. [PubMed]

10. Bao, D.; Gong, M.; Zheng, H.; Chen, M.; Zhang, L.; Wang, H.; Jiang, J.; Wu, L.; Zhu, Y.; Zhu, G.; et al. Sequencing and comparative analysis of the straw mushroom (Volvariella volvacea) genome. PLoS ONE 2013, 8, 1049-1054. [CrossRef] [PubMed]

11. Hou, L.; Li, Y.; Chen, M.; Li, Z. Improved fruiting of the straw mushroom (Volvariella volvacea) on cotton waste supplemented with sodium acetate. Appl. Microbiol. Biotechnol. 2010, 101, 8533-8541. [CrossRef] [PubMed]

12. Kishida, E.; Kinoshita, C.; Sane, Y.; Misaki, A. Structures and antitumor activities of polysaccharides isolated from mycelium of Volvariella volvacea. Biosci. Biotechnol. Biochem. 1992, 56, 1308-1309. [CrossRef] [PubMed]

13. Misaki, A.; Motoko, N.; Yoshiaki, S.; Etsu, K.; Chigusa, K. Comparison of structure and antitumor activity of polysaccharides isolated from Fukurotake, the fruiting body of Volvariella volvacea. Agric. Biol. Chem. 1986, 50, 2171-2183. [CrossRef]

14. Siu, K.C.; Xu, L.; Chen, X.; Wu, J.Y. Molecular properties and antioxidant activities of polysaccharides isolated from alkaline extract of wild Armillaria ostoyae mushrooms. Carbohydr. Polym. 2016, 137, 739-746. [CrossRef] [PubMed]

15. Shashidhar, G.M.; Kumar, S.S.; Giridhar, P.; Manohar, B. Antioxidant and cholesterol esterase inhibitory properties of supplementation with coconut water in submerged cultivation of the medicinal Chinese caterpillar mushroom, Ophiocordy cepssinensis cs 1197 (ascomycetes). Int. J. Med. Mushrooms 2017, 19, 337-345. [CrossRef] [PubMed]

16. Palanisamy, M.; Aldars-García, L.; Gil-Ramírez, A.; Ruiz-Rodríguez, A.; Marín, F.R.; Reglero, G.; Soler-Rivas, C. Pressurized water extraction of $\beta$-glucan enriched fractions with bile acids-binding capacities obtained from edible mushrooms. Biotechnol. Prog. 2014, 30, 391-400. [CrossRef] [PubMed]

17. Roselló-Soto, E.; Parniakov, O.; Deng, Q.; Patras, A.; Koubaa, M.; Grimi, N.; Boussetta, N.; Tiwari, B.K.; Vorobiev, E.; Lebovka, N.; et al. Application of non-conventional extraction methods: Toward a sustainable and green production of valuable compounds from mushrooms. Food Eng. Rev. 2016, 8, 214-234. [CrossRef]

18. Khaskheli, A.A.; Shahzor, G.K.; Liu, Y.; Saghir, A.S.; Wang, Y.F.; Aijaz, H.S.; Tian, X.; Homaida, M.A.; Huang, W. Optimization of enzyme assisted extraction of polysaccharides from Poriacocos. J. Med. Plants Res. 2017, 11, 331-337.

19. Yang, N.; Jin, Y.; Jin, Z.; Xu, X. Electric-field-assisted extraction of garlic polysaccharides via experimental transformer device. Food Bioprocess Technol. 2016, 9, 1612-1622. [CrossRef] 
20. Smiderle, F.R.; Morales, D.; Gil-Ramírez, A.; Jesus, L.I.D.; Gilbert-López, B.; Iacomini, M.; Soler-Rivas, C. Evaluation of microwave-assisted and pressurized liquid extractions to obtain $\beta$-D-glucans from mushrooms. Carbohydr. Polym. 2017, 156, 165-174. [CrossRef] [PubMed]

21. Aguiló-Aguayo, I.; Walton, J.; Viñas, I.; Tiwari, B.K. Ultrasound assisted extraction of polysaccharides from mushroom by-products. LWT-Food Sci. Technol. 2017, 77, 92-99. [CrossRef]

22. Zhao, Z.Y.; Zhang, Q.; Li, Y.F.; Dong, L.L.; Liu, S.L. Optimization of ultrasound extraction of Alisma orientalis polysaccharides by response surface methodology and their antioxidant activities. Carbohydr. Polym. 2015, 119, 101-109. [CrossRef] [PubMed]

23. Zheng, Y.; Li, Y.; Wang, W.D. Optimization of ultrasonic-assisted extraction and in vitro, antioxidant activities of polysaccharides from Trametes orientalis. Carbohydr. Polym. 2014, 111, 315-323. [CrossRef] [PubMed]

24. Alzorqi, I.; Sudheer, S.; Lu, T.J.; Manickam, S. Ultrasonically extracted $\beta$-D-glucan from artificially cultivated mushroom, characteristic properties and antioxidant activity. Ultrason. Sonochem. 2017, 35, 531-540. [CrossRef] [PubMed]

25. Yan, J.K.; Wang, Y.Y.; Qiu, W.Y.; Wang, Z.B.; Ma, H.L. Ultrasound synergized with three-phase partitioning for extraction and separation of Corbicula fluminea polysaccharides and possible relevant mechanisms. Ultrason. Sonochem. 2017, 40, 128-134. [CrossRef] [PubMed]

26. Yang, R.F.; Zhao, C.; Chen, X.; Chan, S.W.; Wu, J.Y. Chemical properties and bioactivities of goji (Lyceum barbarum) polysaccharides extracted by different methods. J. Funct. Foods 2015, 17, 903-909. [CrossRef]

27. Zheng, Q.; Ren, D.; Yang, N.; Yang, X. Optimization for ultrasound-assisted extraction of polysaccharides with chemical composition and antioxidant activity from the Artemisia sphaerocephala Krasch seeds. Int. J. Biol. Macromol. 2016, 91, 856-866. [CrossRef] [PubMed]

28. Xu, Y.; Zhang, L.; Yang, Y.; Song, X.; Yu, Z. Optimization of ultrasound-assisted compound enzymatic extraction and characterization of polysaccharides from blackcurrant. Carbohydr. Polym. 2015, 117, 895-902. [CrossRef] [PubMed]

29. Afshari, K.; Samavati, V.; Shahidi, S.A. Ultrasonic-assisted extraction and in-vitro antioxidant activity of polysaccharide from Hibiscus leaf. Int. J. Biol. Macromol. 2015, 74, 558-567. [CrossRef] [PubMed]

30. Vilkhu, K.; Mawson, R.; Simons, L.; Bates, D. Applications and opportunities for ultrasound assisted extraction in the food industry-A review. Innov. Food Sci. Emerg. 2008, 9, 161-169. [CrossRef]

31. Chen, Y.; Du, X.J.; Zhang, Y.; Liu, X.H.; Wang, X.D. Ultrasound extraction optimization, structural features, and antioxidant activity of polysaccharides from Tricholoma matsutake. J. Zhejiang Univ. Sci. B 2017, 18, 674. [CrossRef] [PubMed]

32. Wang, J.; Zhang, J.; Zhao, B.; Wang, X.; Wu, Y.; Yao, J. A comparison study on microwave-assisted extraction of Potentilla anserina L. polysaccharides with conventional method: Molecule weight and antioxidant activities evaluation. Carbohydr. Polym. 2010, 80, 84-93. [CrossRef]

33. Yan, J.K.; Pei, J.J.; Ma, H.L.; Wang, Z.B. Effects of ultrasound on molecular properties, structure, chain conformation and degradation kinetics of carboxylic curdlan. Carbohydr. Polym. 2015, 121, 64-70. [CrossRef] [PubMed]

34. Feng, S.M.; Luo, Z.S.; Tao, B.P.; Chen, C. Ultrasonic-assisted extraction and purification of phenolic compounds from sugarcane (Saccharum officinarum L.) rind. LWT-Food Sci. Technol. 2015, 60, 970-976. [CrossRef]

35. Samavati, V. Polysaccharide extraction from Abelmoschus esculentus: Optimization by response surface methodology. Carbohydr. Polym. 2013, 95, 588-597. [CrossRef] [PubMed]

36. Chen, W.; Wang, W.P.; Zhang, H.S.; Huang, Q. Optimization of ultrasonic-assisted extraction of water-soluble polysaccharides from boletus edulis, mycelia using response surface methodology. Carbohydr. Polym. 2012, 87, 614-619. [CrossRef]

37. Dean, A.; Voss, D.; Draguljić, D. Design and Analysis of Experiments; Springer: New York, NY, USA, 1999.

38. Cui, F.J.; Li, Y.; Xu, Z.H.; Xu, H.Y.; Sun, K.; Tao, W.Y. Optimization of the medium composition for production of mycelial biomass and exo-polymer by Grifola frondosa GF9801 using response surface methodology. Bioresour. Technol. 2006, 97, 1209-1216. [CrossRef] [PubMed]

39. Villetti, M.A.; Crespo, J.S.; Soldi, M.S.; Pires, A.T.N.; Borsali, R.; Soldi, V. Thermal degradation of natural polymers. J. Therm. Anal. Calorim. 2002, 67, 295-303. [CrossRef] 
40. Yasuo, I.; Toru, T.; Kyuichi, Y.; Atsuya, T.; Teruyuki, K. Control of viscosity in starch and polysaccharide solutions with ultrasound after gelatinization. Innov. Food Sci. Emerg. 2008, 9, 140-146.

41. Cheung, Y.C.; Siu, K.C.; Liu, Y.S.; Wu, J.Y. Molecular properties and antioxidant activities of polysaccharide-protein complexes from selected mushrooms by ultrasound-assisted extraction. Process Biochem. 2012, 47, 892-895. [CrossRef]

42. Colussi, R.; Pinto, V.Z.; Halal, S.L.M.E.; Vanier, N.L.; Villanova, F.A.; Silva, R.M.E.; da Rosa Zavareze, E.; Dias, A.R. Structural, morphological, and physicochemical properties of acetylated high-, medium-, and low-amylose rice starches. Carbohydr. Polym. 2014, 103, 405-413. [CrossRef] [PubMed]

43. Woggum, T.; Sirivongpaisal, P.; Wittaya, T. Characteristics and properties of hydroxypropylated rice starch based biodegradable films. Food Hydrocol. 2015, 50, 54-64. [CrossRef]

44. Sudharsan, K.; Chandra, M.C.; Azhagu, S.B.P.; Archana, G.; Sabina, K.; Sivarajan, M.; Sukumar, M. Production and characterization of cellulose reinforced starch (crt) films. Int. J. Biol. Macromol. 2016, 83, 385-395. [CrossRef] [PubMed]

45. Xu, Y.; Liu, G.; Yu, Z.; Song, X.; Li, X.; Yang, Y.; Wang, L.; Liu, L.; Dai, J. Purification, characterization and antiglycation activity of a novel polysaccharide from black currant. Food Chem. 2016, 199, 694-701. [CrossRef] [PubMed]

46. Li, N.; Chen, F.M.; Cui, F.J.; Sun, W.J.; Zhang, J.S.; Qian, L.S.; Yang, Y.; Wu, D.; Dong, Y.; Jiang, J.; et al. Improved postharvest quality and respiratory activity of straw mushroom (Volvariella volvacea) with ultrasound treatment and controlled relative humidity. Sci. Hortic. 2017, 225, 56-64. [CrossRef]

47. Dubois, M.; Gilles, K.A.; Hamilton, J.K.; Rebers, P.A.; Smith, F. Colorimetric method for determination of sugars and related substances. Anal. Chem. 1956, 28, 350-356. [CrossRef]

48. Box, G.E.P.; Behnken, D.W. Some new three level designs for the study of quantitative variables. Technometrics 1960, 2, 455-475. [CrossRef]

49. Sluiter, A.; Hames, B.; Ruiz, R.; Scarlata, C.; Sluiter, J.; Templeton, D. Determination of Structural Carbohydrates and Lignin in Biomass; National Renewable Energy Laboratory (NREL): Golden, CO, USA, 2008.

50. Barrientos, R.C.; Clerigo, M.M.; Paano, A.M.C. Extraction, isolation and MALDI-QTOFMS/MS analysis of $\beta$-D-glucan from the fruiting bodies of Daedalea quercina. Int. J. Biol. Macromol. 2016, 93, 226-234. [CrossRef] [PubMed]

51. Liu, Z.Q.; Wu, L.; Zheng, L.; Wang, W.Z.; Zhang, X.J.; Jin, L.Q.; Zheng, Y.G. Biosynthesis of tert-butyl (3R,5S)-6-chloro-3,5-dihydroxyhexanoate by carbonyl reductase from Rhodosporidium toruloides in mono and biphasic media. Bioresour. Technol. 2018, 249, 161-167. [CrossRef] [PubMed]

52. Liu, Z.Q.; Dong, S.C.; Yin, H.H.; Xue, Y.P.; Tang, X.L.; Zhang, X.J.; He, J.Y.; Zheng, Y.G. Enzymatic synthesis of an ezetimibe intermediate using carbonyl reductase coupled with glucose dehydrogenase in an aqueous-organic solvent system. Bioresour. Technol. 2017, 229, 26-32. [CrossRef] [PubMed]

53. Liu, Z.Q.; Lu, M.M.; Zhang, X.H.; Cheng, F.; Xu, J.M.; Xue, Y.P.; Jin, L.Q.; Wang, Y.S.; Zheng, Y.G. Significant improvement of the nitrilase activity by semi-rational protein engineering and its application in the production of iminodiacetic acid. Int. J. Biol. Macromol. 2018, 116, 563-571. [CrossRef] [PubMed]

Sample Availability: Not available.

(C) 2018 by the authors. Licensee MDPI, Basel, Switzerland. This article is an open access article distributed under the terms and conditions of the Creative Commons Attribution (CC BY) license (http:/ / creativecommons.org/licenses/by/4.0/). 